\title{
Defining "Haemodynamic Significance" of the Patent Ductus Arteriosus: Do We Have All the Answers?
}

\author{
Aisling Smith ${ }^{a}$ Afif F. EL-Khuffasha, ${ }^{a b}$ \\ ${ }^{a}$ Department of Neonatology, The Rotunda Hospital, Dublin, Ireland; ${ }^{b}$ Department of Paediatrics, School of \\ Medicine, Royal College of Surgeons in Ireland, Dublin, Ireland
}

\section{Keywords}

Patent ductus arteriosus · Premature infant .

Haemodynamic significance

\begin{abstract}
Optimum management of the patent ductus arteriosus (PDA) in preterm infants remains one of the most debated topics within the field of neonatology. Despite numerous observational studies and over 60 randomized control trials, consensus on PDA management remains elusive. In order to make meaningful progress on the controversial issue of PDA management, several key factors must be thoroughly addressed; namely (1) accurate identification of infants at greatest risk of long-term morbidities from PDA exposure, (2) acceptance that the PDA is not a dichotomous entity and an individualised approach to its management is required for each neonate, (3) international consensus on what constitutes a haemodynamically significant PDA and (4) the incorporation of multi-organ assessment when evaluating the impact a PDA may pose on overall neonatal physiology. This review assesses the evidence base available supporting various therapeutic strategies for PDA, the deficits in our current knowledge on the definition of haemodynamic significance and future directions to pursue in order to more successfully address this contentious subject.

(c) 2020 S. Karger AG, Basel
\end{abstract}

\section{Introduction}

Few topics within neonatology have caused such intense debate as the optimum management of the patent ductus arteriosus (PDA). Despite numerous observational studies and over 60 randomized controlled trials (RCTs), consensus on PDA diagnosis and management remains elusive [1]. A cause and effect relationship between a PDA in preterm infants and important short- and long-term morbidities remains unproven; the definition of haemodynamic significance (HS) is not established and our current approach to determining what constitutes HS remains primitive. As a result, none of the therapeutic interventions discussed below have led to a tangible improvement in PDA-related short- and long-term morbidities in preterm neonates.

\section{The Prophylactic, Early Targeted and Conservative Approaches to PDA Management}

The PDA is associated with a number of serious adverse neonatal outcomes in preterm infants, including intraventricular haemorrhage (IVH), periventricular leukomalacia, bronchopulmonary dysplasia, acute kidney injury and necrotising enterocolitis (NEC) [2-4]. As pul- karger@karger.com

(c) 2020 S. Karger AG, Basel

www.karger.com/neo

Karger!
Prof. Afif EL-Khuffash, FRCPI, MD, DCE

Department of Neonatology, The Rotunda Hospital

Department of Paediatrics, Royal College of Surgeons in Ireland

Dublin 1 (Ireland)

afifelkhuffash@rcsi.com 
monary vascular resistance falls over the first few days of age, left-to-right ductal shunting may lead to pulmonary over-circulation and systemic hypoperfusion. PDA management is aimed at reducing the detrimental impact on neonatal haemodynamics and improving prematurity outcomes. Since the 1970s, 3 main PDA management strategies have emerged; namely the prophylactic, early targeted and conservative strategies. The potential benefits of each approach have been evaluated by numerous observational studies and RCTs examining the type, timing, duration and mode of administration of various therapeutic interventions.

The prophylactic approach aims to treat the PDA within the first $24 \mathrm{~h}$ post-delivery, typically without echocardiographic assessment and regardless of its HS [5]. Although prophylaxis with indomethacin demonstrates improved short-term outcomes, including reduced frequency of later PDA treatment (including ligation) and severe IVH, there was no improvement in mortality or longterm morbidities, such as chronic lung disease (CLD) or neurodevelopmental impairment in extremely-lowbirth-weight infants [5-8]. This approach to treatment can also result in closure of vital ducts in the presence of duct-dependent congenital heart disease or in the presence of pulmonary hypertension. With evidence that the prophylactic approach fails to mitigate long-term adverse outcomes and a simultaneous concern among physicians regarding universal cyclo-oxygenase (COX) inhibitor use, the "early targeted" approach to PDA management gained favour. The major advantage of the early targeted approach is that preterm infants with a small or non-haemodynamically significant PDA are not exposed to the potentially detrimental side effects of COX inhibitors, including acute kidney injury, intestinal perforation and thrombocytopenia [9]. However, similar to the prophylactic strategy, studies examining the early targeted approach did not demonstrate improvements in important neonatal outcomes, such as IVH, NEC or retinopathy of prematurity, when compared to expectant management $[10,11]$. Subsequent to these findings, and in combination with the high rates of spontaneous PDA closure noted for babies born less than 29 weeks' gestation, the early targeted strategy was largely superseded by the conservative approach to PDA management in many neonatal units $[12,13]$. The conservative approach aims to ameliorate the effects of left-to-right ductal shunting via various clinical strategies without active medical or surgical management. Such conservative methods are an amalgamation of fluid restriction, diuretics, permissive hypercapnia and maintaining a high positive end expiratory pressure
[14]. The conservative approach has been widely adopted in neonatology, and Bixler et al. [15] documented that from 2006 to 2015, use of indomethacin or ibuprofen decreased from 32 to $18 \%$ and PDA ligation decreased from 8 to $3 \%$ for infants born less than 30 weeks' gestation across 280 neonatal intensive care units in the United States [15]. This shift was mirrored in a Canadian study where conservative PDA management for 5,824 preterm babies born at 23-32 weeks' gestation increased from 14 to $38 \%$ between 2006 and 2012 [16]. However, there is a dearth of evidence to support use of conservative management strategies in preterm infants and the untreated course of the PDA has not been objectively investigated in any treatment trial to date. Therefore, despite years of research, there is no single approach to PDA management with proven safety and reduction in adverse longterm neonatal morbidities that has justified universal endorsement among neonatologists.

\section{Issues with Existing Studies of PDA Management}

The current literature on PDA management permits us to draw a limited number of conclusions. However, the cause and effect relationship between PDA and adverse neonatal outcomes, such as IVH, periventricular leukomalacia and CLD, has yet to be definitively established and existing RCTs of both the prophylactic and early targeted approaches have failed to report a reduction in such morbidities. There remains significant variability in PDA management in neonatology and there are calls to adopt a more uniform approach to diagnosis and management [11].

Two major issues which hinder the relevance and applicability of previous PDA studies are (1) open treatment of placebo groups in RCTs and (2) significant heterogeneity in the definition of PDA HS.

\section{Open Treatment of Placebo Groups in RCTs}

In 2015, Evans pointed out that "Neonatologists have been reluctant to engage in trials that test treatment against almost never treating" [17]. The open-label treatment and intention to treat analysis of placebo groups in RCTs has rendered the ability to draw concrete conclusions from these groups next to impossible. It is estimated that in some studies $>50 \%$ of control subjects receive open label PDA treatment, thereby potentially diluting the beneficial effect of PDA treatment in the intervention group and terminating thorough evaluation of the natural evolution of the untreated PDA in preterm infants 
Fig. 1. Ideal PDA trial design. Important factors need to be considered at all stages of trial design in order to definitively determine if PDA treatment results in a reduction in neonatal morbidity. None of the trials to date have adopted this approach. PDA, patent ductus arteriosus; hs, haemodynamic significance; CLD, chronic lung disease; NEC, necrotising enterocolitis; PVL, periventricular leukomalacia; ND, neurodevelopmental.

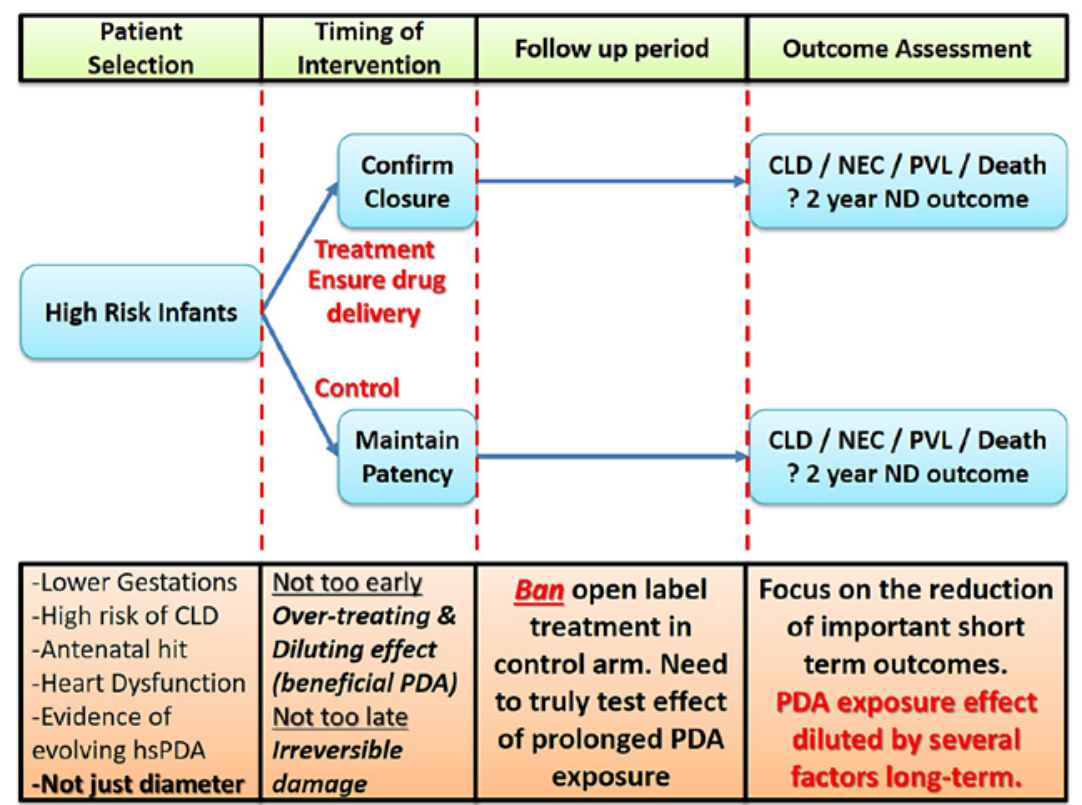

\section{Comprehensive and Multimodal Assessment of HS PDA}

There is a growing consensus among neonatologists that in order to make meaningful progress on the controversial issue of PDA management, there are several key factors that must be thoroughly addressed; namely (1) accurate identification of infants at greatest risk of longterm morbidities from PDA exposure, (2) acceptance that the PDA is not a dichotomous entity and an individualised approach to its management is required for each neonate, (3) international consensus on what constitutes an HS PDA and (4) the incorporation of multi-organ assessment when evaluating the impact a PDA may pose on overall neonatal physiology (Fig. 2).

The concept of HS incorporates several intrinsic and extrinsic factors that require accurate assessment and quantification. To date, this has proven a challenge, which is underpinned by the failure to recognise the important elements that warrant consideration: (1) PDA shunt volume and its impact on the systemic and pulmonary circulations [23]; (2) myocardial function evaluation, in particular the relationship between left ventricular (LV) diastolic function in the setting of increased pulmonary blood flow in addition to the contribution of the PDA shunt to coronary ischaemia [24]; and (3) clinical charac- 


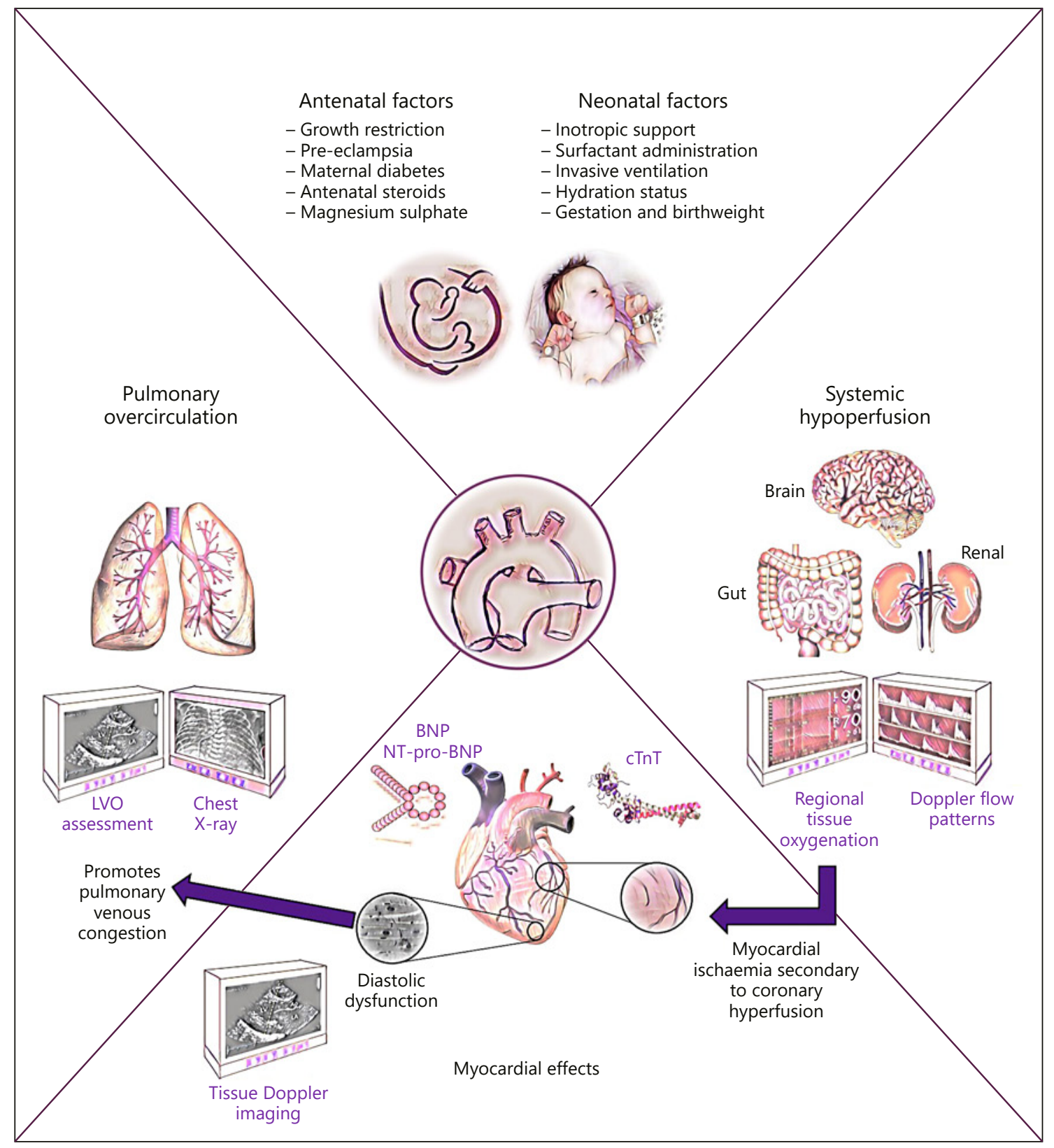

Fig. 2. Determinants of haemodynamic significance. The concept of haemodynamic significance is a complex one made of several interconnected components. A holistic approach to determine significance is needed. LVO, left ventricular output; BNP, B-type natriuretic peptide; NT-pro-BNP, N-terminal pro-B-type natriuretic peptide; cTnT, Cardiac troponin T.

teristics which can alter the relationship between a PDA and its physiological impact [25]. The use of multimodal technologies may provide a superior and more robust evaluation of PDA impact. Such multi-organ evaluation may include biomarkers, echocardiography, Doppler ultrasound of the renal and cerebral blood flow and nearinfrared spectroscopy (NIRS) [25].

\section{Echocardiographic Assessment of HS}

Neonatal echocardiography is the gold standard for PDA diagnosis, assessment of haemodynamic impact on the preterm circulation and monitoring therapeutic response [26]. Thorough echocardiographic evaluation of ductal significance must incorporate markers of pulmo- 
nary over-circulation, systemic hypoperfusion and characterisation of the duct itself, including diameter and Doppler flow pattern [27]. Echocardiographic surrogates for pulmonary over-circulation include left atrial to aortic root ratio (LA:Ao), LV output, LV end diastolic diameter, mitral valve $\mathrm{E}$ and $\mathrm{A}$ velocities and isovolumic relaxation time [28].

Echocardiographic indices assessing systemic hypoperfusion include interrogation of the peak systolic velocity and diastolic flow direction in the descending aorta and renal, coeliac and middle cerebral arteries. Echocardiography and colour Doppler ultrasound can be used to assess the effect of HS PDA on end organ perfusion and function. Colour Doppler demonstrates that the PDA reduces middle cerebral artery blood flow velocity in verylow-birth-weight neonates in the first 5 days of age [29]. It was previously thought that the PDA would only exert negative effects on the blood flow of post-ductal vessels; however, a 2017 study reported that a persistent PDA by days 5-7 of age was also associated with reversed diastolic flow in the brachiocephalic artery [30].

A vital and often forgotten component of the assessment of the HS of a PDA is myocardial performance. The inherent systolic and, more importantly, diastolic dysfunction that is ubiquitous in preterm infants in addition to the effect a PDA has on coronary artery perfusion must be taken into consideration $[31,32]$. The presence of diastolic dysfunction in the setting of increased pulmonary blood flow can promote pulmonary venous hypertension, which in turn can increase RV afterload resulting in compromised right ventricular (RV)-pulmonary artery coupling. RV-pulmonary artery coupling refers to the increase in RV contractility in the face of increasing RV afterload up to a certain threshold. Any further increase in afterload beyond this threshold results in compromised contractility (decoupling). The presence of LV diastolic compromise results in a reduction of this decoupling threshold. Evolving pulmonary venous hypertension secondary to impaired LV diastolic function can therefore impair RV performance [33]. This can have significant clinical implications, such as an increase in the incidence of pulmonary haemorrhage and prolonging the need for ventilation [34]. In the setting of a PDA, decoupling could be further exacerbated due to the inability of the stiff LV to accommodate an increasing pulmonary venous return. Recent evidence also suggests that infants with lower diastolic function assessed using tissue Doppler imaging are more likely to suffer from PDA-related morbidities such as CLD [35]. This highlights the importance of considering LV diastolic function in the definition of HS [35]. In addition, left-to-right shunting across a PDA can compromise coronary artery perfusion resulting in subclinical myocardial ischaemia and further compromise in systolic and diastolic function in this setting $[36,24]$. Therefore, incorporating the measurement of myocardial function in the overall assessment of HS of a PDA should be adopted.

\section{Near-Infrared Spectroscopy}

NIRS is a non-invasive technology that continuously measures regional tissue oxygenation. Studies have investigated the utility of this technique in the determination of PDA significance and the evaluation of treatment response [37]. NIRS has the ability to detect HS PDArelated systemic hypoperfusion with a 2016 study reporting that NIRS derived renal oxygen saturation measurements $<66 \%$ identified a HS PDA with a sensitivity of $81 \%$ and specificity of $77 \%$ in 47 babies born less than 29 weeks' gestation and a 2017 study reporting a significant relationship between reversed diastolic flow in the descending aorta secondary to a HS PDA and low mesenteric regional oxygenation $[38,39]$. Research with NIRS to assess the long-term effects of HS PDA on cerebral perfusion and brain growth is ongoing. Lemmers et al. [40] investigated NIRS-derived cerebral oxygen saturation ( $\mathrm{rSco} 2$ ) measurements in 3 groups of preterm babies; Group 1 closed their PDA with indomethacin treatment, Group 2 required additional surgical closure for their PDA and Group 3 were matched controls without a PDA. With 140 babies included, their study demonstrated that the surgery group had the lowest $\mathrm{rSco} 2 \mathrm{mea}-$ surements before PDA closure $(n=35$, mean \pm SD, $48 \pm$ 9.7\%) compared with the indomethacin $(n=35,59 \pm$ $10.4 \% ; p<0.001)$ and control groups $(n=70,66 \pm 6.9 \%$; $p<0.001)$ and the lowest brain volumes of most brain regions at term-equivalent age as evaluated by magnetic resonance imaging. A similar finding was reported by Poon and Tagamolila [41] who evaluated the impact of HS PDA by NIRS regional cerebral saturation measurements and fractional tissue oxygenation extraction (FTOE) before and after medical and/or surgical treatment. Although this study reported no association between PDA diameter and NIRS measurements, there was a significant increase in cerebral oxygen saturation values and a decrease in FTOE measurements following PDA closure. Cohen et al. [42] also reported that, although small-for-gestational-age preterm babies show higher cerebral oxygenation than their appropriate-for- 
gestational-age counterparts over the first days of life, they still experienced a significant reduction in regional cerebral oxygen saturation values measured by NIRS and an associated rise in cerebral FTOE in the context of an HS PDA. Such cerebral NIRS data support the hypothesis that systemic steal due to a HS PDA can cause impaired oxygen delivery to brain tissues, decreased brain volumes and exert a potentially negative effect on future neurodevelopmental outcomes.

However, adequate oxygen delivery to the tissues is influenced by many physiological variables, including the fluid status, haemoglobin level, respiratory support, cardiac function and auto regulatory capacity of the baby. Other studies have countered that echocardiographic indices of ductal significance may not necessarily directly correlate with compromised cerebral oxygenation measurements. Schwarz et al. [43] reported that the "oxygen transport capacity of the blood" may confound interpretation of NIRS data, while a 2016 study demonstrated similar cerebral and renal NIRS measurements between infants with a closed duct, non-HS PDA and HS PDA [27]. This emphasises that the complexity of neonatal haemodynamics and ductal steal is just one component influencing adequate blood flow and oxygen delivery to neonatal tissues. A broad view of neonatal physiology must be assumed when determining ductal significance, and NIRS may prove to be most useful when combined with available clinical, biochemical and echocardiographic measurements.

\section{Biomarkers for PDA Assessment}

Biomarkers have been used alone and in combination with echocardiography to diagnose ductal significance. There is an association between left atrial enlargement secondary to PDA and elevated plasma concentrations of atrial natriuretic peptide [44]. Urinary excretion of Btype natriuretic peptide (BNP), which is synthesized in the ventricles secondary to PDA-induced volume overload, is also significantly higher in infants with mediumto-large PDA compared to those with small PDA [45]. Cardiac troponin $\mathrm{T}$ ( $\mathrm{cTnT}$ ) levels are also significantly correlated with PDA diameter, LA:Ao and descending aortic end diastolic velocity [46]. Additionally, in a group of infants born less than 32 weeks' gestation, El-Khuffash et al. [47] documented that serum cTnT and N-terminal pro-BNP levels and an echocardiography-derived PDA risk score were higher in their severe disability/death group at 2 years of age compared to their normal $/ \mathrm{mild}$ disability group. Such data support the potential utility of such relatively easily obtained biomarkers in a comprehensive assessment of ductal significance.

\section{Future Directions for PDA Management}

Therapeutic decision-making must shift from the assumption that preterm infants form a homogenous population and that the PDA is a simplistic entity whose haemodynamic impact is sufficiently evaluated by sole assessment of ductal diameter. Clinicians should embrace a holistic, multi-organ assessment of ductal impact, an approach that must encompass clinical and echocardiographic indices of pulmonary over-circulation and systemic hypoperfusion, an appraisal of myocardial performance, with potential input from emerging technologies such as NIRS. There is an emerging body of evidence to support adopting this holistic approach to PDA management. A recent study devised a PDA severity score from 141 infants born less than 29 weeks' gestation incorporating markers of LV diastolic function and pulmonary over-circulation in addition to accounting for the gestation of the infant at the time of assessment. When a cut-off score of 5 is applied within this model, the later occurrence of CLD/death may be predicted from day 2 with a sensitivity and specificity of 92 and 87\%, respectively [36]. Such PDA severity scores aid early detection of infants who may benefit from PDA closure while also recognising that those with non-HS PDA may be justifiably managed with a conservative approach. In addition, future studies should focus on banning PDA treatment in the control arms to really assess the effect of prolonged PDA exposure. Although over 60 RCTs have been conducted to date, a true conservative versus active treatment trial of PDA has not been performed wherein there is no open label treatment of the placebo group. One such study has been registered in the Netherlands, and if the conservative group remains truly untreated in this multicentre trial, it could yield valuable insights into the natural history of the duct [48]. With ongoing improvements in available PDA surgical closure options, there will also be scope to investigate the merits of device closure versus medical treatment in future years [49].

In conclusion, neonatologists must continue to pursue an individualistic approach to PDA management. PDA severity risk scores can encompass a holistic strategy that assesses the multi-organ impact of ductal shunting, pinpoint those infants who will benefit from therapeutic intervention and permit treatment to be targeted based on HS. Such PDA severity scoring systems will require rigor- 
ous evaluation through RCTs and should ideally be compared against a conservatively managed group of preterm infants with no open label treatment. In this context, significant advancements may be achieved on elucidating ideal clinical management of the PDA.

\section{Disclosure Statement}

The authors declare that there are no conflicts of interest.

\section{Funding Sources}

No funding was received for this study.

\section{Author Contributions}

A.S. wrote the first draft and edited the final manuscript. A.E. devised the concept and structure of the review, edited the final version and approved the overall paper.

\section{References}

1 Mitra S, Florez ID, Tamayo ME, Mbuagbaw L, Vanniyasingam T, Veroniki AA, et al. Association of placebo, indomethacin, ibuprofen, and acetaminophen with closure of hemodynamically significant patent ductus arteriosus in preterm infants: a systematic review and meta-analysis. JAMA. 2018 Mar; 319(12):1221-38.

2 Evans N, Kluckow M. Early ductal shunting and intraventricular haemorrhage in ventilated preterm infants. Arch Dis Child Fetal Neonatal Ed. 1996 Nov;75(3):F183-6.

3 Härkin P, Marttila R, Pokka T, Saarela T, Hallman M. Morbidities associated with patent ductus arteriosus in preterm infants. $\mathrm{Na}$ tionwide cohort study. J Matern Fetal Neonatal Med. 2018 Oct;31(19):2576-83.

4 Majed B, Bateman DA, Uy N, Lin F. Patent ductus arteriosus is associated with acute kidney injury in the preterm infant. Pediatr Nephrol. 2019 Jun;34(6):1129-39.

5 Schmidt B, Davis P, Moddemann D, Ohlsson A, Roberts RS, Saigal S, et al.; Trial of Indomethacin Prophylaxis in Preterms Investigators. Long-term effects of indomethacin prophylaxis in extremely-low-birth-weight infants. N Engl J Med. 2001 Jun;344(26): 1966-72.

6 Schmidt B, Asztalos EV, Roberts RS, Robertson CM, Sauve RS, Whitfield MF; Trial of Indomethacin Prophylaxis in Preterms (TIPP) Investigators. Impact of bronchopulmonary dysplasia, brain injury, and severe retinopathy on the outcome of extremely low-birthweight infants at 18 months: results from the trial of indomethacin prophylaxis in preterms. JAMA. 2003 Mar;289(9):1124-9.

7 Gournay V, Roze JC, Kuster A, Daoud P, Cambonie G, Hascoet JM, et al. Prophylactic ibuprofen versus placebo in very premature infants: a randomised, double-blind, placebocontrolled trial. Lancet. 2004 Nov;364(9449): 1939-44.

8 Ding Y, Wang X, Wu Y, Li H, Xu J, Wang X. Effects of prophylactic oral ibuprofen on the closure rate of patent ductus arteriosus in premature infants. Medicine (Baltimore). 2018 Sep;97(37):e12206.
9 El-Mashad AE, El-Mahdy H, El Amrousy D, Elgendy M. Comparative study of the efficacy and safety of paracetamol, ibuprofen, and indomethacin in closure of patent ductus arteriosus in preterm neonates. Eur J Pediatr. 2017 Feb;176(2):233-40.

10 Sosenko IR, Fajardo MF, Claure N, Bancalari E. Timing of patent ductus arteriosus treatment and respiratory outcome in premature infants: a double-blind randomized controlled trial. J Pediatr. 2012 Jun;160(6):92935.e1.

11 Edstedt Bonamy AK, Gudmundsdottir A, Maier RF, Toome L, Zeitlin J, Bonet M, et al.; collaborators from the EPICE Research Group. Patent ductus arteriosus treatment in very preterm infants: a European populationbased cohort study (EPICE) on variation and outcomes. Neonatology. 2017;111(4):367-75.

12 Koch J, Hensley G, Roy L, Brown S, Ramaciotti C, Rosenfeld CR. Prevalence of spontaneous closure of the ductus arteriosus in neonates at a birth weight of 1000 grams or less. Pediatrics. 2006 Apr;117(4):1113-21.

13 Kluckow M, Jeffery M, Gill A, Evans N. A randomised placebo-controlled trial of early treatment of the patent ductus arteriosus. Arch Dis Child Fetal Neonatal Ed. 2014 Mar; 99(2):F99-104.

14 Smith A, McNamara PJ, El-Khuffash AF Non-pharmacological management of a hemodynamically significant patent ductus arteriosus. Semin Fetal Neonatal Med. 2018 Aug;23(4):245-9.

15 Bixler GM, Powers GC, Clark RH, Walker MW, Tolia VN. Changes in the diagnosis and management of patent ductus arteriosus from 2006 to 2015 in United States neonatal intensive care units. J Pediatr. 2017 Oct;189:10512.

16 Lokku A, Mirea L, Lee SK, Shah PS; Canadian Neonatal Network. Trends and outcomes of patent ductus arteriosus treatment in very preterm infants in Canada. Am J Perinatol. 2017 Apr;34(5):441-50.

17 Evans N. Preterm patent ductus arteriosus: A continuing conundrum for the neonatologist? Semin Fetal Neonatal Med. 2015 Aug; 20(4):272-7.
18 Sankar MN, Bhombal S, Benitz WE. PDA: to treat or not to treat. Congenit Heart Dis. 2019 Jan; 14(1):46-51.

19 Prescott S, Keim-Malpass J. Patent ductus arteriosus in the preterm infant: diagnostic and treatment options. Adv Neonatal Care. 2017 Feb;17(1):10-8.

20 El-Khuffash A, Weisz DE, McNamara PJ. Reflections of the changes in patent ductus arteriosus management during the last 10 years. Arch Dis Child Fetal Neonatal Ed. 2016 Sep; 101(5):F474-8

21 Zonnenberg I, de Waal K. The definition of a haemodynamic significant duct in randomized controlled trials: a systematic literature review. Acta Paediatr. 2012 Mar;101(3):24751.

22 Shepherd JL, Noori S. What is a hemodynamically significant PDA in preterm infants? Congenit Heart Dis. 2019 Jan;14(1):21-6.

23 McNamara PJ, Sehgal A. Towards rational management of the patent ductus arteriosus: the need for disease staging. Arch Dis Child Fetal Neonatal Ed. 2007 Nov;92(6):F424-7.

24 Sehgal A, McNamara PJ. Coronary artery perfusion and myocardial performance after patent ductus arteriosus ligation. J Thorac Cardiovasc Surg. 2012 Jun;143(6):1271-8.

25 Kluckow M, Lemmers P. Hemodynamic assessment of the patent ductus arteriosus: beyond ultrasound. Semin Fetal Neonatal Med. 2018 Aug;23(4):239-44.

26 de Boode WP, Kluckow M, McNamara PJ, Gupta S. Role of neonatologist-performed echocardiography in the assessment and management of patent ductus arteriosus physiology in the newborn. Semin Fetal Neonatal Med. 2018 Aug;23(4):292-7.

27 van der Laan ME, Roofthooft MT, Fries MW, Berger RM, Schat TE, van Zoonen AG, et al. A hemodynamically significant patent ductus arteriosus does not affect cerebral or renal tissue oxygenation in preterm infants. Neonatology. 2016;110(2):141-7.

28 Yap N, Bharucha T. Patent ductus arteriosus in extreme prematurity: role of echocardiography and other imaging techniques. Curr Pediatr Rev. 2016;12(2):126-35. 
29 Weir FJ, Ohlsson A, Myhr TL, Fong K, Ryan ML. A patent ductus arteriosus is associated with reduced middle cerebral artery blood flow velocity. Eur J Pediatr. 1999 Jun;158(6): 484-7.

30 Breatnach CR, Franklin O, McCallion N, ElKhuffash A. The effect of a significant patent ductus arteriosus on Doppler flow patterns of preductal vessels: an assessment of the brachiocephalic artery. J Pediatr. 2017 Jan;180: 279-81.e1.

31 Noori S, Seri I. Pathophysiology of newborn hypotension outside the transitional period. Early Hum Dev. 2005 May;81(5):399-404.

32 Fanaroff JM, Fanaroff AA. Blood pressure disorders in the neonate: hypotension and hypertension. Semin Fetal Neonatal Med. 2006 Jun;11(3):174-81.

33 Bussmann N, El-Khuffash A, Breatnach CR, McCallion N, Franklin O, Singh GK, et al. Left ventricular diastolic function influences right ventricular - Pulmonary vascular coupling in premature infants. Early Hum Dev. 2019 Jan; 128:35-40.

34 Bussmann N, Breatnach C, Levy PT, McCallion N, Franklin O, El-Khuffash A. Early diastolic dysfunction and respiratory morbidity in premature infants: an observational study. J Perinatol. 2018 Sep;38(9):1205-11.

35 El-Khuffash A, James AT, Corcoran JD, Dicker P, Franklin O, Elsayed YN, et al. A patent ductus arteriosus severity score predicts chronic lung disease or death before discharge. J Pediatr. 2015 Dec;167(6):1354-61. e2.
36 El-Khuffash A, Davis PG, Walsh K, Molloy EJ. Cardiac troponin T and N-terminal-pro-B type natriuretic peptide reflect myocardial function in preterm infants. J Perinatol. 2008 Jul;28(7):482-6.

37 Garvey AA, Kooi EM, Smith A, Dempsey EM. Interpretation of cerebral oxygenation changes in the preterm infant. Children (Basel). 2018 Jul;5(7):E94.

38 Chock VY, Rose LA, Mante JV, Punn R. Nearinfrared spectroscopy for detection of a significant patent ductus arteriosus. Pediatr Res. 2016 Nov;80(5):675-80.

39 Ledo A, Aguar M, Núñez-Ramiro A, Saénz P, Vento M. Abdominal near-infrared spectroscopy detects low mesenteric perfusion early in preterm infants with hemodynamically significant ductus arteriosus. Neonatology. 2017;112(3):238-45.

40 Lemmers PM, Benders MJ, D’Ascenzo R, Zethof J, Alderliesten T, Kersbergen KJ, et al. Patent ductus arteriosus and brain volume. Pediatrics. 2016 Apr;137(4):e20153090.

41 Poon WB, Tagamolila V. Cerebral perfusion and assessing hemodynamic significance for patent ductus arteriosus using near infrared red spectroscopy in very low birth weight infants. J Matern Fetal Neonatal Med. 2019 Jul; $1-6$, Epub ahead of print.

42 Cohen E, Dix L, Baerts W, Alderliesten T, Lemmers $\mathrm{P}$, van Bel F. Reduction in cerebral oxygenation due to patent ductus arteriosus is pronounced in small-for-gestational-age neonates. Neonatology. 2017;111(2):126-32.
43 Schwarz CE, Preusche A, Wolf M, Poets CF, Franz AR. Prospective observational study on assessing the hemodynamic relevance of patent ductus arteriosus with frequency domain near-infrared spectroscopy. BMC Pediatr. 2018 Feb;18(1):66.

44 Andersson S, Tikkanen I, Pesonen E, Meretoja $\mathrm{O}$, Hynynen M, Fyhrquist F. Atrial natriuretic peptide in patent ductus arteriosus. $\mathrm{Pe}$ diatr Res. 1987 Apr;21(4):396-8.

45 Khan SS, Sithisarn T, Bada HS, Vranicar M, Westgate PM, Hanna M. Urinary NT-proBNP levels and echocardiographic parameters for patent ductus arteriosus. J Perinatol. 2017 Dec;37(12):1319-24.

46 El-Khuffash AF, Molloy EJ. Influence of a patent ductus arteriosus on cardiac troponin $\mathrm{T}$ levels in preterm infants. J Pediatr. 2008 Sep; 153(3):350-3.

47 El-Khuffash AF, Slevin M, McNamara PJ, Molloy EJ. Troponin T, N-terminal pro natriuretic peptide and a patent ductus arteriosus scoring system predict death before discharge or neurodevelopmental outcome at 2 years in preterm infants. Arch Dis Child Fetal Neonatal Ed. 2011 Mar;96(2):F133-7.

48 Hundscheid T, Onland W, van Overmeire B, Dijk P, van Kaam AH, Dijkman KP, et al. Early treatment versus expectative management of patent ductus arteriosus in preterm infants: a multicentre, randomised, non-inferiority trial in Europe (BeNeDuctus trial). BMC Pediatr. 2018 Aug;18(1):262.

49 Pamukcu O, Tuncay A, Narin N, Baykan A, Korkmaz L, Argun M, et al. Patent Ductus Arteriosus closure in preterms less than $2 \mathrm{~kg}$ : surgery versus transcatheter. Int J Cardiol. 2018 Jan;250:110-5. 